\title{
NIETZSCHE E O PROTO-PERSPECTIVISMO DE ZUR TELEOLOGIE ${ }^{1}$
}

Ricardo Bazilio Dalla Vecchia (UFG) ${ }^{2}$

ricardovecchia@gmail.com

Resumo: Mediante a análise da coletânea de notas "Zur Teleologie" este artigo sugere a existência de um "proto-perspectivismo" na concepção ficcionalista de organismo formulada por Nietzsche no final da década de 1860. Nossa investigação se inicia com uma exposição da oposição entre mecanicismo e teleologia na modernidade, analisa brevemente as posições de Kant e Schopenhauer sobre ela e então as contrasta com a posição de Nietzsche.

Palavras-chave: Nietzsche; Kant; teleologia; perspectivismo.

\section{INTRODUÇÃO}

Em carta endereçada ao amigo e confidente Erwin Rohde, em 03 de abril de 1868, o recém-formado filólogo Nietzsche comenta a possibilidade de doutorar-se em filosofia: "Ademais, tenho pensado que poderia doutorar-me também um dia em filosofia, e assim justificar posteriormente a minha carteira de estudante em Bonn e Leipzig, onde sempre perambulava como stud. philos" (KSB, II, p. 265). Dias depois, agora tendo como destinatário Paul Deussen, a intenção inicial passa a ser tratada como um projeto, com tema e re-

\footnotetext{
${ }^{1}$ Recebido: 27-12-2016/ Aceito: 08-01-2017/ Publicado on-line: 19-01-2017.

${ }^{2}$ Ricardo Bazilio Dalla Vecchia é Professor Adjunto na Universidade Federal de Goiás, Goiânia, GO, Brasil.
} 
corte:

Quando você receber ao final deste ano a minha tese de doutorado perceberás que o problema dos limites do conhecimento se explica em diversos pontos. Meu tema é "o conceito de orgânico a partir de Kant”, metade filosófico, metade ciência da natureza (halb philosophisch, halb naturwissenschaftlich). Minhas preliminares (Vorarbeiten) estão quase prontas. (KSB, II, p. 269)

Por motivos diversos, como os que envolvem a sua indicação à Universidade da Basileia em $1869^{3}$, Nietzsche acaba por declinar do projeto. Antes disso, porém, ele redige algumas "preliminares", um conjunto de notas preparatórias que ficariam conhecidas na fortuna crítica como "Zur Teleologie" (doravante ZT) ${ }^{4}$. A despeito de sua constituição deveras incipiente, ZT constitui um documento de importância estratégica no período de gestação da primeira filosofia de Nietzsche, já que dele se pode depreender uma posição inicial do filósofo acerca do funcionamento da natureza.

À esteira do debate filosófico que na modernidade polarizou as concepções do mecanicismo e da teleologia, $\mathrm{Ni}$ etzsche elaborará uma noção alternativa de organismo,

\footnotetext{
${ }^{3}$ Em outra carta a Rohde, Nietzsche lamenta: "Assim querido amigo repito: nossas perspectivas não deram certo [...]” (KSB, II, p. 272, Tradução nossa). Curt Paul Janz comenta que nesta época, por exemplo, Nietzsche cogitara abandonar os estudos de filosofia para dedicar-se às ciências naturais. In: JANZ, C. P. Nietzsche biographie Enfance, Jeunesse, Les Annees Baloises. Trad. Marc B. de Launay. Paris: Gallimard, 1984, p. 208. Já T. Brobjer chama a atenção para odesejo de Nietzsche de mudar-se para a França: „In 1867 and 1868, Nietzsche planned to go to Paris to study and work fora year. His plans about what to study varied (although classical philology wasalways the most obvious alternative), and in a number of letters he referred with pleasure to the idea of working in Parisian libraries". In: BROBJER, Thomas. Nietzsche's philosophical context: an intellectual biography. Chicago: University of Illinois Press, 2008, p. 42.

${ }^{4}$ A coletânea de notas está registrada na edição completa de Colli e Montinari nos apontamentos 1868, 62 [3] - 62 [57]. Cf. NIETZSCHE, F. Werke: Kritische Gesamtausgabe (KGW). 36 Bände. Herausgeben Giorgio Colli e Mazzino Montinari. Berlim: De Gruyter, 1967-2001, Bd. I. Para uma melhor exposição, no corpo do texto faremos referência apenas ao número do apontamento.
} 
balizada pela recepção de Goethe e Lange, de modo a erigir, segundo penso, uma espécie de "protótipo" ou primeiro esboço de seu perspectivismo maduro. $\mathrm{O}$ contexto geral dessa discussão, seus interlocutores e o posicionamento de $\mathrm{Ni}$ etzsche constitui o horizonte de investigação deste artigo.

\section{NIETZSCHE: UM MODERNO ENTRE OS MODERNOS}

\section{Tendo como referência ZT ${ }^{5}$, Kevin Hill (2003) afirma que} no final da década de 1860 também o pensamento de $\mathrm{Ni}$ etzsche reverberou o espírito de "regresso a Kant" patrocinado, por exemplo, por Kant und die Epigonen (1865), de Otto Liebmann. Esse "revival" da filosofia crítica, aliás, animou parte das discussões filosóficas na segunda metade do séc. XIX, num movimento de oposição ao idealismo alemão e ao romantismo em prol das ciências naturais ${ }^{6}$, al-

\footnotetext{
${ }^{5}$ De acordo com Hill (2003, p. 84) a coletânea se estrutura em três partes, por sua vez divididas do seguinte modo: 1 . Introductory remarks titled 'On Teleology' containing quotes from Schopenhauer's 'Criticism of the Kantian Philosophy', his discussion of the third Critique (WWRi. 529-34). 2. Historical remarks titled 'Teleology since Kant' under which we find the following headings and discussions: A. 'Nature-philosophical' containing three quotations from Schopenhauer, section 28 of the first volume of World as Will and Representation, where he discusses teleology (WWRi. 53-61). B. 'Designed' (Zweckmaßig) containing one quotation from Lange, a reference to Strauss's remarks about Brockes, two quotes from the third Critique (CJ, Ak. v. 3756), one quotation and one citation from Goethe (Princeton Goethe, xii. 31, 64), extensive quotation from Fischer's discussion of the 'Dialectic of Teleological Judgement', in volume two of his Kant book and two quotes from Schopenhauer's 'On Teleology' (WWRii. 327-41). C. Brief notes titled 'Goethe's attempt' including one quotation from the third Critique (CJ, Ak. v. 384). D. A discussion of the conflict between mechanistic and teleological explanation titled 'A False Alternative' including four more quotes from Fischer's discussion of the third Critique. E. Nietzsche's own account of teleology, including two quotes from Fischer's discussion of teleology, and one quotation from Fischer's discussion of Kant's Universal Natural History in volume one, one quotation from Kant taken from Fischer, six quotes from the third Critique (CJ, Ak. v. 378-9, 381, 384), and one paraphrase (of CJ, Ak. v. 425, 2nd para.). 3. An outline or outlines of the proposed dissertation. I am inserting the title and possible reference to parts, deleting explanatory marginalia, and paraphrasing some chapter titles. Since the outlines for what I am calling 'Part I' and 'Part II' are separated by several chapters, perhaps 'Part II' was a fresh attempt at 'Part I'.

${ }^{6}$ Sobretudo em virtude do avanço nas pesquisas referentes à embriologia, química e fisiologia, Cont.
} 
go que na obra de Nietzsche será acentuado no período intermediário.

Para além do séc. XIX, Marques (2003) considera que ao enveredar na discussão sobre a teleologia Nietzsche se coloca na trilha do programa teórico da modernidade, e toma parte no grande embate protagonizado por Leibniz e os "modernos" (mais especificamente Descartes), que trata do antagonismo entre teleologia e mecanicismo. Num esforço de síntese, o comentador português resume esse antagonismo no seguinte dilema filosófico: "[...] ou o mundo é constituído por uma multiplicidade de espontaneidades absolutas que em si tem inscritas a finalidade de seu agir, ou o mundo será sempre a obra de um Deus criador de uma obra imperfeita" (Marques, 2003, p. 22) ${ }^{7}$. Em resposta a isSO:

[De um lado temos]

a) o sujeito não está inscrito na cadeia de causas e efeitos e é-lhe heterogêneo,

b) o particular é contingente em face das leis do sujeito (natureza disponível),

c) ocasionalismo,

d) o mundo é uma série ilimitada que o sujeito representa e ordena

\footnotetext{
afirmações de ordem normativa e descritiva sobre o mundo orgânico e inorgânico passam a reverberar em textos filosóficos como p. ex. as Logische Untersuchungen (1840) de Adolf Trendelenburg, que tenta coadunar os avanços da ciência experimental à filosofia de Aristóteles. As Logische Untersuchungen de Adolf Trendelenburg são nominalmente mencionadas em ZT. Sobre Trendelenburg e seu contexto teórico, cf.: PORTA, Mario Ariel Gonzalez. Estudos Neokantianos. São Paulo: Loyola, 2011.

${ }^{7} \mathrm{Na}$ verdade, embora o comentador não se estenda até este ponto, a oposição ao "radicalismo mecanicista" dos modernos pelo "radicalismo teleológico" de Leibniz já é uma tréplica, na medida em que a tensão primeira, de importância constitutiva para o pensamento moderno, polariza tal "radicalismo mecanicista" e a teleologia antiga, principalmente de proveniência aristotélica. Ou seja, além de uma tensão entre concepções e pensadores no interior da filosofia moderna, a discussão sobre a "constituição do mundo" com a qual amplamente dialoga ZT, demarca as próprias fronteiras entre o pensamento moderno e a filosofia anterior.
} 
segundo um método.

Do outro lado temos sumariamente:

a) um sujeito participante na cadeia de causas e efeitos,

b) um particular não contingente em face dos princípios do sujeito (este não a representa como disponível),

c) um pré-formismo,

d) a afirmação de um todo a realizar como substância ou multiplicidade infinita de substâncias.

O significado de teses teleológicas sobre a historicidade de um mundo cada vez mais sujeito à dominação do sujeito auto-afirmativo pode aparecer como algo aparentemente episódico, mas acabará por revelar-se como o verdadeiro pulsar de uma racionalidade em que o problema do antropocentrismo não pode ser facilmente elidido. (Marques 2003, p. 19)

Os quatro primeiros tópicos resumem a concepção do mecanicismo, particularmente do modo como o entende Descartes; os quatro últimos sintetizam a teleologia, articulada por Leibniz. A oposição entre o mecanicismo e a teleologia constitui uma das principais antinomias do pensamento moderno. Para Nicolai Hartmann (1966), ela decorre da tentativa do pensamento de compreender o mundo a favor de sua unidade, ainda que o próprio mundo não ofereça nenhuma espécie de apoio para isso; essa tentativa, aliás, constitui o próprio assunto de ZT.

Marques (2003) defende que a filosofia de Nietzsche, sobretudo sua "teoria do conhecimento" - o perspectivismo, representa a radicalização do processo de autoafirmação do sujeito moderno, o que o coloca a par e passo com a tradição racionalista crítica. Mesmo antes de sua estreia filosófica em O Nascimento da Tragédia, e isso atesta ZT, por sua preocupação com as "teses sobre a historicidade", Nietzsche se revela não somente um pensador que herdou problemas modernos, mas um (radical) pensador moderno 
a lidar com problemas modernos.

\section{PerspeCtivismo E AUTOAFIRMAC̣ÃO DO SUJEITO}

Para respaldar a sua posição, Marques (2003, p. 16) justifica que é necessário "captar na própria estrutura da autoafirmação moderna uma direção, uma motivação profunda, um conjunto de potencialidades que de forma clara se vinculem ao eclodir do perspectivismo nietzschiano". A conexão proposta por Marques (2003) é a filosofia de Kant, ou melhor, a "figura-tipo" da razão kantiana, que encarna a autoafirmação do sujeito. Para ele, a razão kantiana representa um verdadeiro "epítome da autoafirmação da modernidade", na medida em que desfaz algumas oposições fundamentais da racionalidade moderna (como a que polariza a teleologia e o mecanicismo), apresentando uma novidade absoluta e uma ruptura com a tradição da teleologia do substancialismo de procedência aristotélica.

Grosso modo, essa novidade consiste em conceber o sujeito auto-afirmativo no limiar de uma situação antinômica: o sujeito auto-afirmativo é o culminar do processo em que a razão compreende a si mesma constituída por antinomias que devem ser resolvidas, uma razão que compreende suas contradições e coloca a si mesma como objeto para realizar uma autocrítica:

Mas a verdade é que o processo de auto-afirmação do sujeito é o de uma racionalidade autocrítica que se vê a si mesma como antinômica e reduzindo seu próprio campo. Até se poderá considerar que o culminar da modernidade na obra kantiana se traduz numa situação de negatividade em face das pretensões de uma racionalidade sem obstáculos, isto é, sem autoconscienscialização de antinomias constitutivas de si própria. Kant vê, no entanto, um valor positivo nas res- 
trições que a razão impõe a si mesma. (Marques 2003, p. 18)

Embora abalizada por sua própria crítica (negativa), a razão kantiana encontra um "porto seguro" para a sustentação de seu empreendimento teórico e prático na medida em que institui a forma pela qual o sujeito conhece. A revolução copernicana de Kant ao situar a lei, o universal, ao lado do sujeito e não mais do objeto, do em-si, alcança algo intrinsecamente positivo, que auxilia a razão no seu processo de "superar seus próprios pontos de vista ilusórios, seus excessos unilaterais" (Marques 2003, p. 18). Dentre os "excessos unilaterais" da razão encontra-se a oposição entre teleologia e mecanicismo, frente à qual o próprio Kant se posiciona de modo diverso ao longo de sua filosofia.

Desde o início de sua reflexão Kant é confrontado com esse dilema da escolha entre uma perda da possibilidade de sentido por sua crítica ao paradigma teleológico moderno de um Leibniz e entre a consequente aceitação de um formalismo do relacionamento temporal por um lado e por outro um pré-formismo do sentido em que toda a teleologia dogmática se revê. A primeira crítica surge como um momento significativo do triunfo daquele formalismo, mas o passo decisivo, aquele em que o dilema tomou uma forma antinômica racional e decidível, foi dado na obra que fecha o sistema crítico, a Crítica da Faculdade do Juízo. (Marques 2003, p. 39)

$\mathrm{Na}$ Crítica da razão pura, fiel à sua teoria da experiência e ao paradigma newtoniano da ciência da natureza, Kant permanece atado ao formalismo, cuja célebre asserção sintetiza:

[...] A razão só entende aquilo que produz segundo os seus próprios planos; ela tem que tomar a dianteira com princípios, que determinam os seus juízos segundo leis constantes e deve forçar a natureza a responder às suas interrogações em vez de se deixar guiar por esta; de outro modo, as observações feitas ao acaso, realizadas sem plano pré- 
vio, não se ordenam segundo a lei necessária, que a razão procura e de que necessita. A razão, tendo por um lado os seus princípios, únicos a poderem dar aos fenômenos concordantes a autoridade de leis e, por outro, a experimentação, que imaginou segundo esses princípios, deve ir ao encontro da natureza, para ser por esta ensinada, é certo, mas não na qualidade de aluno que aceita tudo o que o mestre afirma, antes na de juiz investido nas suas funções, que obriga as testemunhas a responder aos quesitos que lhes apresenta. (Kant 2008, B XIII)

No formalismo da primeira crítica a resposta às interrogações da razão é plena "quando a natureza e também a vida social, jurídica e ética são por inteiro submetidas a uma legislação de essência universal que um sujeito autônomo encontra em sua esfera” (Marques 2003, pp. 17-18). A autonomia desse sujeito "equivale à universalidade de suas leis", portanto se trata de um sujeito formal, "dotado de leis gerais", um "espaço em que se organizam e sistematizam essas leis":

A Crítica da Faculdade do Juizo, sob o título de uma crítica à teleologia objetiva e constituinte que ocupa sua segunda metade, vai alargar os limites da experiência legal possível e, ao fazê-lo, alarga também a autonomia da racionalidade do sujeito afirmativo [...] e mostra que certas aporias nos domínios quer teórico, quer prático só se resolvem pela subjetivização das formas do real, isto é, pela aceitação de uma exterioridade (o espaço e o tempo) como formas em que o que é real (como fenômeno) está subordinado ao sujeito ou a suas categorias (Marques 2003, p. 43)

Mediante o alargamento da experiência legal pela subjetivização das formas do real, a terceira crítica passa a compreender a razão como uma faculdade de sistematização, por conseguinte "representar a natureza como um todo que se especificasse em leis particulares será um princípio utilizado pela razão que não terá valor objetivo, mas somente sub- 
jetivo" (Ibid). A partir disso, a natureza deixa de ser concebida como um todo que se especifica em gêneros, para ser julgada apenas "como se" ela realmente fosse assim":

Do ponto de vista do sujeito auto-afirmativo, a introdução do princípio do como se, meramente regulador, revela uma extensão da atividade daquele ao domínio da sistemática, ao plano superior a que Kant chama a arte dos sistemas. Para além disso, será interessante notar que, se, por um lado, parece haver uma concessão à existência de uma legislação exterior ao sujeito, isto é, a uma natureza que tem suas próprias leis de especificação, por outro lado, essa concessão é só aparente, já que a expressão "como se" devolve ao sujeito o princípio que, só por uma questão de método se atribuiu à natureza. (Idem, p. 44)

A solução que Kant encontra na terceira crítica para o antagonismo entre teleologia radical e mecanicismo radical consiste em "manter a teleologia nos limites do sujeito legislador, ainda que se trate de uma teleologia, por assim dizer, fraca" (Idem, p. 45). Nessa "teleologia fraca" do sujeito legislador "as leis da natureza são as minhas leis, o meio em que tudo aparece é o meu plano transcendental, as ligações, sínteses nesse meio, no espaço e no tempo, são feitas de acordo com as minhas categorias" (Idem, p. 50).

Esta subjetivação corrobora com a perda de sentido da razão, na medida em que faz desaparecer os fins, a própria lógica que sustenta a harmonia das partes no todo, a teleologia, isto é, "na nossa relação teorética com o ser os fins reais desaparecem" (Ibid), ou melhor, são deslocadas ao mundo noumenal da razão prática.

Por outras palavras, a razão, em seu caminho de superação da posi-

\footnotetext{
${ }^{8}$ É esta noção de "todo", de "orgânico" o que Nietzsche pretendia investigar em ZT, abalizado por Kant.
} 
ção teleológica dogmática, reduz a textura do mundo às formas mais gerais (categorias) do conhecimento das coisas como objetos. Mas, justamente nesse movimento de superação, dá-se conta de sua atitude unilateral, ao deparar com o fato de existirem particulares que permanecem contingentes (por assim dizer, inexplicáveis) em face dessas leis sumamente gerais. E é a repentina constatação de que na natureza algo existe que não é simplesmente redutível às leis do entendimento que obriga a uma nova auto-reflexão da racionalidade moderna. (Marques 2003, p. 51)

Seguindo o percurso sugerido por Marques (2003), na história da "radicalização da modernidade" a emergência de um princípio de finalidade da natureza enfraquecido como o que se apresenta na terceira crítica de Kant deixa o rastro para que Schopenhauer substancialize no conceito de Vontade a categoria suprema de ser, subjetivizada por Kant.

Como se lê no $\S 18$ de O Mundo como vontade e como representação:

De fato, a busca da significação do mundo que está diante de mim simplesmente como minha representação, ou a transição dele, como mera representação, nunca seria encontrada se o investigador, ele mesmo, nada mais fosse senão o puro sujeito que conhece. Contudo, ele mesmo se enraíza neste mundo, encontra-se nele como indivíduo, isto é, seu conhecimento, sustentáculo condicionante do mundo inteiro como representação, é no todo intermediado por um corpo, cujas afecções, como se mostrou, são para o entendimento o ponto de partida da intuição no mundo. [...] todo ato verdadeiro de sua vontade é simultânea e inevitavelmente também um movimento de seu corpo. Ele não pode realmente querer o ato sem ao mesmo tempo perceber como este aparece como movimento corporal. $\mathrm{O}$ ato da vontade e a ação do corpo não são dois estados diferentes, conhecidos objetivamente e vinculados pelo nexo da causalidade; nem se encontram na relação de causa e efeito; mas são uma única e mesma coisa [...]. (Schopenhauer 2005, p. 157)

Ao afirmar que todo ato de vontade individual é uma 
objetivação da vontade metafísica através do corpo, Schopenhauer "radicaliza um certo subjetivismo contido no idealismo transcendental de Kant, ao retirar substancialidade a certas categorias que tornavam possível a objetividade como tal", e assim "restaura uma teleologia forte, um finalismo da substância, ao determinar a vontade como coisa em si" (Marques 2003, p. 53).

A despeito de seu passo atrás em relação à teleologia fraca de Kant, a teleologia de Schopenhauer, ao distinguir na natureza orgânica em geral entre duas espécies de finalidades, a interna e a externa, abrirá um importante precedente:

Essa finalidade é dupla. De um lado é interna, ou seja, uma concordância ordenada de todas as partes de um organismo isolado, de modo que tanto a sua conservação quanto a de sua espécie dependem disso e, por conseguinte, o organismo expõe a si mesmo como fim dessa ordenação; de outro é externa, ou seja, uma relação da natureza inorgânica para com a orgânica em geral, ou também uma relação entre si de partes isoladas da natureza orgânica que torna possível a conservação de toda a natureza orgânica [...]. (Schopenhauer 2005, p. 220)

A dupla finalidade dos produtos orgânicos da natureza deixa transparecer não só a ideia da intenção final de autopreservação presente na natureza, mas, também, que o conceito de fim em Schopenhauer é uma mera vontade de viver, e aqui nos aproximamos de Nietzsche:

O princípio de uma vontade de viver parece ser a chave para compreender a constituição de uma teoria do conhecimento nietzschiana. Efetivamente, esse princípio concentra em si dois aspectos fundamentais que irão decerto motivar o aparecimento daquela teoria: 1) o esvaziamento de sentido de uma teleologia do mundo pensada na base da mera vontade de viver, o que significaria, em última 
análise, um finalismo que se anula em seus próprios termos, já que a vida tem-se por fim a si mesma; 2) o retrocesso em direção à vontade para a explicação da atividade cognitiva vai conferir uma feição utilitária ou instrumental àquilo a que Kant chamava o interesse da razão, expresso naquelas ideias reguladoras, justamente ficções da razão com vista ao conhecimento de mais alto nível, que é o sistemático. (Marques 2003, p. 54)

Para Marques (2003, p. 54) a "teoria nietzschiana do conhecimento" incorpora os dois elementos arrolados na citação anterior, a saber, a impossibilidade de uma explicação teleológica e a intensificação do lado subjetivo dos conceitos supremos da razão. Exatamente neste ponto o comentador português faz uma breve menção à ZT afirmando que já ali "Nietzsche realiza um trabalho que concretamente procura circunscrever o estatuto subjetivoutilitário daquilo que para Kant tinha ainda um valor, por assim dizer, cognitivo puro”. Para justificar a sua afirmação, o intérprete envereda numa revisão da ideia de organismo na terceira crítica kantiana confrontando-a com a "teoria do conhecimento" de Nietzsche, mas não se debruça especificamente sobre os apontamentos de ZT, o que me proponho a fazer em virtude do entendimento de que ali se encontram os primeiros antecedentes do perspectivismo de $\mathrm{Ni}$ etzsche.

\section{ZuR Teleologie: NiETZSCHE CONTRA Kant}

O título do primeiro apontamento 62 [3] "Zur Teleologie", embora tenha se consagrado como o título de todo o manuscrito, apenas remete ao horizonte amplo de investigação de Nietzsche, que se especifica no terceiro apontamento 62 [6] "Die Teleologie seit Kant", mas que, de acordo com o pró- 
prio filósofo na já citada carta a Deussen destina-se a tratar do "conceito de orgânico a partir de Kant".

$\mathrm{Na}$ verdade, o foco específico de discussão de ZT é a noção kantiana de conformidade a fins na natureza, sobretudo no modo como ela se apresenta na Crítica da faculdade de julgar. Como vimos brevemente, na terceira crítica Kant admite ser possível estabelecer princípios regulativos para um conhecimento teleológico da natureza, mesmo que eles, por não terem como base os dados da intuição, não venham a constituir um conhecimento objetivo, determinante.

Esses princípios regulativos, da ordem do juízo reflexivo, permitem estabelecer uma espécie de "critério de validade subjetivo" para conhecimentos que a razão julga necessários em sua compreensão da natureza. Isso basicamente significa que o investigador "forja" uma imagem orgânica da natureza para justificar a interação mecânica de suas diferentes partes. Assim, a razão não apenas encontra limites na explicação mecânica do mundo, mas em virtude de sua própria estrutura acaba por atribuir à natureza uma intencionalidade, uma conformidade a fins, como lemos na seção 76:

[...] Já que a dedução das leis particulares a partir das universais, a

\footnotetext{
${ }^{9}$ De acordo com Toscano (2001, p. 38) ZT pode ser lida a partir de três significados: "1) significado interno. As notas 1868 seriam lidas como precursoras do envolvimento posterior de Nietzsche com as ciências naturais, com as questões da teleologia e individuação. 2) Significado Conjuntural. As notas seriam lidas como sintomas de um compromisso contemporâneo com a questão da teleologia. As notas de Nietzsche seriam o traço distante e um pouco inexperiente do debate sobre a individualidade que sustentou a relação entre as ciências biológicas e a filosofia durante todo o século XIX alemão. 3) Significado conceitual. As notas seriam lidas como uma concatenação singular de três elementos conceituais em um problema filosófico verdadeiro [materialismo, individuação e teleologia, RBDV]".
} 
respeito daquilo que aquelas contem em si de contingente, é impossível a priori através da definição do conceito do objeto, então o conceito de conformidade a fins da natureza nos seus produtos torna-se necessário para a faculdade de juízo humana, em relação à natureza, mas não um conceito dizendo respeito à determinação dos próprios objetos. Torna-se por isso um princípio subjetivo da razão para a faculdade de juízo, o qual, na qualidade de regulativo (não constitutivo), é valido do mesmo modo necessariamente para a nossa faculdade de juízo humana, como se se tratasse de um princípio objetivo. (Kant 2012, p. 275)

Os conceitos regulativos são necessários à faculdade de juízo humana e capazes de orientar a investigação da natureza. Esses conceitos operam por um princípio teleológico na medida em que representam as coisas como seres organizados em seus fins naturais, ou seja, as partes dos produtos da natureza são pensadas umas em função das outras, e em função do todo, como instrumento - organismo.

Em sua leitura abalizada por K. Fischer, Lange e Schopenhauer, Nietzsche vislumbra um grave problema na concepção kantiana de orgânico, na medida em que ela faz conviver duas proposições contraditórias, a saber: i) a de que o organismo não pode ser compreendido pelo viés de uma causalidade estritamente mecânica; ii) a de que o próprio conhecimento depende de se estabelecer um juízo determinante que leva em conta causas e efeitos, operando justamente no âmbito do mecanicismo. Esse entrave é o ponto de partida de ZT, para elucidação do qual Nietzsche recorrerá a um vasto repertório de influências ${ }^{10}$, dais quais destacamos inicialmente Schopenhauer.

\footnotetext{
${ }^{10}$ Ao longo do manuscrito Nietzsche faz menção a uma série de obras e interlocutores, de diferentes áreas. Apenas como exemplo podemos mencionar: Lotze, Herbart, Herder, Johannes Müller, Jakob Fries e Lorenz Oken.
} 


\section{No $§ 27$ do Mundo lemos:}

[...] Em todas as ideias, vale dizer em todas as forças da natureza inorgânica e em todas as figuras da natureza orgânica, é uma única e mesma vontade que se manifesta, noutros termos, que entra na forma de representação, na objetidade. Em consequência, sua unidade também tem de ser reconhecida por intermédio de um parentesco interior entre todos os seus fenômenos. Tal parentesco se manifesta nos graus mais elevados de sua objetidade em que todo fenômeno é mais distinto, portanto nos reinos vegetal e animal, por meio da analogia geral prevalecente de todas as formas: o tipo fundamental que se encontra em todos os fenômenos. (Schopenhauer 2005, p. 207)

Para a metafísica voluntarista de Schopenhauer, uma "única e mesma vontade" está a se objetivar dos graus mais inferiores do mundo inorgânico aos mais elevados do reino vegetal, animal e humano, sendo que a cada um desses graus corresponde uma ideia. Neste processo de objetivação a Vontade una:

[...] Renuncia aos graus mais baixos de seu fenômeno, após um conflito entre eles, para assim aparecer num grau mais elevado e tanto mais poderoso. [...] Conforme o organismo consiga maior ou menor dominação daqueles graus mais básicos das forças da natureza que expressam a objetidade da vontade, torna-se a expressão mais ou menos perfeita de sua Idéia. (Schopenhauer 2005, p. 211)

Para Schopenhauer o organismo é o resultado de um processo conflituoso de dominação e assimilação das ideias inferiores pelas superiores, do mais baixo inorgânico ao perfectível orgânico. A partir disso, Araldi (2007, p. 36) vislumbra a possibilidade de estabelecer um vínculo entre Schopenhauer e Nietzsche:

À semelhança de Schopenhauer, também para o jovem Nietzsche todos os fenômenos do mundo - desde as forças do mundo inorgânico até os organismos mais bem estruturados dos reinos vegetal e 
animal - expressam uma mesma vontade. Há, assim, um parentesco, uma afinidade entre todas as aparições da vontade na natureza orgânica, graças ao tipo fundamental (a Ideia) que subjaz a todas elas.

No encalço de Schopenhauer, o jovem Nietzsche haveria preservado a concepção de que todos os fenômenos do mundo são expressões de uma "mesma vontade". Diferenciando-se de seu primeiro mestre, porém, Nietzsche afirma que esse conflito se dá no plano da imanência, ou seja, o impulso que conforma o organismo proviria dele mesmo, por isso não se trata de um ser ou vontade superior a organizar o mundo e a estabelecer fins para ele, mas de um conflito, desde o inorgânico passando para o orgânico, em que de modo imanente as forças superiores vão dominando as inferiores ${ }^{11}$, por conseguinte:

À diferença de Schopenhauer, que via no mundo fenomenal apenas a manifestação da vontade de viver cega, geradora de múltiplos sofrimentos, o jovem filósofo-filólogo vê nas relações de forças - desde as combinações químicas do mundo inorgânico até as mais elaboradas formações orgânicas - um jogo artístico de coesão e separação, de construção e destruição. (Araldi 2007, p. 35)

Esta breve digressão já antecipa três características da noção de organismo que Nietzsche distinguirá em ZT, a saber, de que o organismo é: i) o produto de um conflito (Schopenhauer); ii) uma soma (Virchow) de forças imanen-

\footnotetext{
${ }^{11}$ O protótipo desta noção de organismo como soma de forças provém da obra do médico alemão Rudolf Virchow (1821-1902), que Nietzsche conhece através de Lange. Para Virchow os organismos são produzidos pela soma de unidades vitais dentre as quais não é possível identificar um centro, o que inviabiliza a possibilidade de uma direção única e predeterminada ao organismo. Lange em sua História do Materialismo pondera que a teoria de Virchow concomitante aos desenvolvimentos da teoria celular desmonta o finalismo aristotélico, considerando como "místico" o princípio de dominação do todo pela parte.
} 
tes; iii) sem uma finalidade externa ${ }^{12}$. Afirmar o contrário seria incorrer numa posição de tonalidade metafísica, como a de Leibniz, da qual Nietzsche busca igualmente escapar.

Um organismo, no sentido de uma configuração regular, persistente, raciocina Nietzsche, não é algo em absoluto necessário, mas fruto de uma ocasional dominação de forças sobre forças. Na verdade, e aqui está o ponto crucial em que Nietzsche se aproxima e se afasta de Kant, a "organicidade" do orgânico é estabelecida pelo intelecto humano. Esse intelecto, porém, postula a regularidade, a necessidade, o "todo" de sua experiência meramente acidental, contingente:

Kant procura justificar "que existiu uma necessidade de pensarmos os organismos como predeterminados, ou seja, com conceitos teleológicos". Posso apenas admitir que isso é uma maneira de se explicar a Telelologia. Além disso, a analogia com a experiência humana apenas expõe o surgimento (Entstehung) ocasional/arbitrário, isto é, não mediatizado, da adequação, por exemplo, na feliz conjunção entre talento e destino, jogo de loteria. Ou seja: na infinita plenitude dos casos efetivos, estes devem ser favoráveis ou adequados. A necessidade da qual Kant fala, raramente existe em nossa época: mas, pensemos que mesmo Voltaire mantém a justificativa telelológica como insuperável. Otimismo e Telelologia caminham juntos, no sentido de contestar a não-conformidade a fins como algo realmente não conforme a fins. (KGW, I, 62 [3])

Já no primeiro apontamento de ZT, Nietzsche apresenta a sua objeção central à teleologia kantiana, no fundo, uma objeção ampla às tentativas de explicação orgânicas do mundo, na maior parte das vezes radicadas num pressuposto racional ou transcendente. Nietzsche aqui parece anco-

\footnotetext{
${ }^{12}$ Essa concepção imanente enseja uma espécie de "mecanicismo" ou "materialismo" que ZT não dá conta de justificar, e que precisará ainda ser enfrentada no decorrer da obra.
} 
rar-se em dois pressupostos: i) a reserva feita pelo próprio Kant na terceira crítica, de que o conceito de fins no organismo é um conceito de ordem subjetiva, produto de um ato reflexivo da razão, que não pode construir um conhecimento objetivo sobre o mundo, tampouco sobre causas superiores da natureza como a finalidade; ii) a premissa, de procedência darwinista, de que a combinação entre mecanicismo e acaso seria suficiente para explicar a formação do organismo, sem recorrer à hipótese finalista de uma causalidade inerente à natureza ${ }^{13}$.

Por isso, como observa Nietzsche no último apontamento, conceber a existência de fins nos corpos naturais é uma postura autorreferente que explica apenas a própria teleologia, reiterando os seus pressupostos. Para Nietzsche, portanto, o sujeito "finge" encontrar fora de si os fins que ele mesmo, de modo fictício, criou, servindo-se da estratégia de tomar o não intencional como inconveniente:

Em geral a arma contra a teleologia é: a prova da não-conformidade a fins.

Assim só será evidenciado que a maior razão atua apenas esporadicamente, e que também existe uma área para uma razão inferior. Portanto, não há uma teleologia uniforme: [há] apenas uma inteligência criadora.

Tal hipótese é construída segundo uma analogia humana: porque não pode haver um poder inconsciente, que tem em vista a criação, isto é, natureza: pense-se no instinto dos animais. Esse é o ponto de vista da filosofia natural.

Também já não se coloca o ato de conhecer fora do mundo.

Mas nos colocamos na metafísica e devemos recorrer à coisa em si.

Finalmente, pode haver uma possível solução em um ponto de vista

\footnotetext{
${ }^{13}$ Este apoio inicial no darwinismo será revisto, sobretudo na década de 1880 , quando Nietzsche trava contato com as ciências naturais de autores como Roux, Virchow e Bernard.
} 
estritamente humano: o empedocleano, onde o finalista só aparece como um caso sob muitos não-conforme a fins.

Duas soluções metafísicas foram tentadas:

Uma delas, mais ou menos antropológica, coloca um homem ideal fora do mundo; a outra, metafísica, recorre a um mundo inteligível em que o fim é imanente às coisas.

A conformidade a fins é a exceção.

A conformidade a fins é casual.

Ela revela uma irracionalidade completa.

É preciso retirar todo o interesse teológico da questão. (KGW, I, 62 [4])

Para o jovem Nietzsche de ZT, a prova da nãoconformidade a fins (Nachweis des Unzweckmäßigen) é a prova contra a teleologia, a necessidade mesma do pensamento teleológico, pois estabelece que não há uma uniformidade teleológica na natureza. A conformidade a fins (Zweckmäßige), a "lei", é na verdade casual (zufällig), contingente, uma mera exceção (Ausnahmefall), um acaso favorável daquilo que é irracional (Unvernunft) ${ }^{14}$, no sentido de ser algo desprovido de qualquer razão ou impossível de ser categorizado por ela, logo:

O surgimento do organismo não nos obriga a supor uma causalidade agindo em conformidade a fins, ou seja, um entendimento ou razão; tal surgimento pode ser explicado pela combinação de hipóteses mecânicas com a noção de acasos favoráveis. A vida pode ser então interpretada como uma ocorrência entre inúmeras possíveis. Este cenário elimina, portanto, a necessidade de conceber a natureza como um sistema de fins e com ela toda referência a uma conformida-

\footnotetext{
${ }^{14}$ A prova do inconveniente parece ser ainda um ataque velado de Nietzsche ao neo-kantismo, sobretudo a Trendelenburg cuja explicação filosófica da vida orgânica se respalda na posição teleológica de J. P. Müller (1801-1858) que além de um finalismo concebe ainda um todo racional a responder pela origem e desenvolvimento dos organismos. Para Nietzsche é esse tipo de metafísica e sua lógica que sustentam a noção de necessidade que a prova do inconveniente vem a descaracterizar.
} 
de a fins externa. Se esta argumentação é sólida, então não há mais necessidade de se preocupar com um eventual aproveitamento teológico de juízos de finalidade fundados na analogia técnica (Lopes 2008, p. 148).

No apontamento 62 [4] Nietzsche avalia as duas soluções modernas sobre os fins da natureza, o mecanicismo e a teleologia, respectivamente considerando a primeira mais antropológica por colocar um homem ideal fora do mundo e a segunda mais metafísica, por estabelecer uma finalidade imanente às coisas. De acordo com ele, embora difiram quanto ao locus da finalidade, dentro ou fora do homem, ambas as soluções ao já pressuporem a possibilidade dessa finalidade, propósito, desígnio (Zweck), incorrem, por vias diferentes, no mesmo erro: tanto a "solução" mais antropológica (a do "radicalismo mecanicista" do cogito cartesiano) quanto a mais metafísica (do "radicalismo teleológico" das mônadas de Leibniz) são igualmente metafísicas.

A partir dessa avaliação, Nietzsche formula seus três principais argumentos: i) "A intencionalidade do orgânico e a regularidade do inorgânico são trazidas à natureza por nossa razão" (KGW, I, 62 [7]); ii) "Não temos direito a qualquer julgamento sobre a intencionalidade maior" (KGW, I, 62 [12]); iii) "A teleologia assim como o otimismo é um produto estético” (KGW, I, 62 [16]).

Equacionados, esses argumentos conduzem àquela que provavelmente seria a tese de Nietzsche, e que, segundo me parece, constitui o protótipo do perspectivismo que reverberará ao longo de todo o período jovem e intermediário: a intencionalidade do orgânico e a regularidade do inorgânico são trazidas à natureza por nossa razão (como já ponderara Kant), isto é, são produtos de um juízo reflexivo (e não 
determinante), subjetivo da razão, que confere leis à natureza sem as ir retirar dela.

O projeto de investigar o conceito de orgânico desde Kant leva Nietzsche, já em 1868, a acercar-se de uma postura que se poderia designar "pré-perspectivista" uma vez que prevê que as leis da natureza ou conceitos gerais como o de "orgânico" não passam de ficções produzidas pelo intelecto. Sobre isso observa R. Lopes (2008, p. 152):

O caráter indeterminado desta categorização permite a Nietzsche questionar um dos grandes dogmas do kantismo, a antítese entre mecanismo e teleologia, ou melhor, entre juízo determinante e juízo reflexivo. Ao longo de boa parte das notas preparatórias Nietzsche parece aderir à concepção dicotômica de Kant, que restringe o conceito de explicação ao emprego da causalidade mecânica expressa no juízo determinante. Contudo, na progressão das notas Nietzsche toma uma direção inversa e sugere uma redução das causas mecânicas a causas finais e do uso constitutivo ao uso reflexivo da faculdade de julgar [...] $\mathrm{O}$ que está sendo proposto nesta redução não é um alargamento do conceito de explicação, para que este pudesse abranger também os juízos de finalidade. Trata-se antes de um movimento contrário, que torna despovoada a classe dos juízos explicativos e parece culminar em Nietzsche na sugestão de que o conceito de explicação seja inteiramente substituído pelo conceito de interpretação.

O protótipo do perspectivismo de ZT parece residir precisamente na tese de que os juízos explicativos quedam "despovoados" frente ao caráter indeterminado de nossas categorizações. O homem não tem nenhum direito a um julgamento objetivo sobre a intencionalidade maior da natureza, pois essa intencionalidade não provém da natureza; ela é criada e condicionada pelo próprio aparelho conceitual e perceptivo do homem, de modo ficcional.

A disposição orgânica (teleológica ou mecanicista) é fruto de uma "imaginação estendida", uma ficção criada pelo 
homem para poder regular o seu conhecimento e as suas ações. No fundo, não há conhecimento no sentido usual do postura correspondencialista, mas somente interpretação, ficcionalização. "O conceito de orgânico é apenas humano [...]” (KGW, I, 62 [27]), um jogo artístico, uma criação fictícia; a teleologia e o otimismo são meramente produtos estéticos, ficções:

A vida, o organismo, não provam qualquer inteligência superior: não há contínuos graus de inteligência em tudo.

A existência de organismos só mostra as forças cegas em efetivação.

1. Eliminação da imaginação estendida da teleologia.

2. Fronteiras do conceito. A conformidade a fins na natureza.

3. Intencional é igual a capaz de existência.

4. Organismos como multiplicidades e unidades.

A imaginação do todo considerado como causa é o fim.

NB: Mas o "todo" em si é apenas uma imaginação. (KGW, I, 62 [34])

Se a noção de uma teleologia natural possibilitou a Kant pensar em conceitos subjetivos fundamentais à razão, o conceito de conformidade a fins, visto como um produto estético, passa a ser a expressão de um poder inconsciente, que cria e se serve do conhecimento para as funções vitais como fortalecimento, crescimento, preservação. Trata-se de um princípio vital, ou como Nietzsche diz no apontamento 62 [29]: "Aqui verifica-se que acabamos de chamar proposital o que é viável. O segredo é apenas 'vida'”. Lopes (2008) chama a atenção para o teor pós-kantiano do alargamento do juízo reflexivo, que reverbera p. ex. na filosofia da natureza de Schelling, mas que vincula Nietzsche especialmente a outro filósofo determinante para toda esta discussão:

Lange concorda com este diagnóstico e, como vimos, restringe a fantasia especulativa ao âmbito do discurso edificante e da ficção con- 
ceitual. Contudo, Lange não considera que o discurso científico opere com categorias que se distinguem por princípio das ficções conceituais da filosofia. Uma oposição semelhante à que vigora na ortodoxia kantiana, entre a função constitutiva das categorias do entendimento e a regulativa das ideias da razão, não tem lugar no programa de renovação da filosofia crítica esboçado por Lange, que tem como uma de suas metas superar o rígido dualismo kantiano entre corpo e mente e a divisão esquemática do psiquismo em faculdades cujas atividades estariam submetidas a princípios transcendentais autônomos. Também aqui Nietzsche deve ser visto como um herdeiro do programa de Lange: ao problematizar a distinção kantiana entre uso regulativo e determinante dos juízos, Nietzsche dá um passo decisivo rumo a uma compreensão ficcional generalizada dos processos de assimilação humana do mundo. (Lopes 2008, p. 153)

Embora não seja citado em nenhum apontamento, ao lado de Schopenhauer F. Lange é uma das influências mais marcantes de $\mathrm{ZT}^{15}$. A oportuna (e velada) influência de Lange fornecerá a Nietzsche um modelo alternativo para pensar o problema do organismo, que ele absorverá quase sem reservas.

\section{ZUR TELEOLOGIE: GOETHE CONTRA SCHOPENHAUER}

A partir da segunda metade de ZT Nietzsche passa a estabelecer uma inusitada interlocução com os escritos sobre ciências da natureza de Goethe, na tentativa de consolidar uma posição anti-metafísica sobre o orgânico, como se lê no

\footnotetext{
${ }^{15}$ Neste sentido, pondera Toscano (2001, p. 39): “O que os livros de notas registram de maneira impressionante são os efeitos de dois verdadeiros acontecimentos na biografia intelectual de $\mathrm{Ni}$ etzsche, tomando a forma de dois livros cujas ideias, de forma bastante heterogênea, vão assombrar o seu trabalho até o fim: $O$ Mundo como Vontade e Representação de Arthur Schopenahauer e História do Materialismo de Friedrich Albert Lange". Sobre a relação entre Nietzsche e Lange Cf.: SALAQUARDA, J. Nietzsche und Lange. In: NS 7, 1978, pp. 236-253. STACK, G. Lange and Nietzsche. Berlin: de Gruyter, 1983.
} 
apontamento 62 [31], que tem como subtítulo justamente "Experimentos de Goethe": “[...] porque podemos desintegrar qualquer coisa mecanicamente, em consequência disso não acredito mais em fins".

Enquanto a metafísica voluntarista de Schopenhauer promovia a ideia de que o organismo não é um conceito da cognição, já que há uma vontade onipresente a organizar o mundo, a teoria da natureza de Goethe fornece a Nietzsche um modelo alternativo de indivíduo e de organismo não caudatários da teleologia, mas algo da ordem da imanência, do natural, como interação de forças, para respaldar a sua própria ideia. Mais ainda. Se Schopenhauer auxiliou Nietzsche na tentativa de rejeitar a noção de organismo kantiana, as ideias sobre a formação dos organismos de Goethe o permitem escapar do pessimismo de Schopenhauer sobre os efeitos da vontade, percebendo assim, desde cedo, o caráter ficcional dos conceitos constitutivos:

O conceito do todo não está nas coisas, mas em nós. Estas unidades que chamamos de organismos também são multiplicidades. Não há individualidade da realidade, mas indivíduos e organismos não são nada mais que abstrações. (KGW, I, 62 [28])

A estratégia de Nietzsche ao recorrer a Goethe é de fato inusitada, porém não original, posto que antes dele Lange já a havia proposto. O capítulo sobre Darwinismo e teleologia da História do Materialismo de Lange é "[...] sem dúvida a principal fonte de inspiração para muitas das observações de Nietzsche sobre Kant e a teleologia" (Toscano, 2001, p. 49), como a inteligente recorrência à noção pluralista de Goethe para confrontar a metafísica de Schopenhauer, e também a remissão a Virchow no argumento a favor da 
ideia de organismo como modelo para a construção das unidades.

Além disso, como sintetiza Toscano (2001, p. 50), diferente de Schopenhauer, Lange também mostra a Nietzsche que:

Para começar, em vez de ser delimitado e submetido à hegemonia do principium individuationis, o domínio da representação e experiência é tanto relativizado (como uma "consequência de nossa organização") e desancorado de sua dependência em última instância a uma irrepresentável e sem fundamento unidade sem multiplicidade, se esta for concebida como vontade ou como "unidade absoluta da auto-consciência”. A atribuição da unidade se torna uma ilusão objetiva gerada por uma constituição físico-transcendental, mas não há nenhuma necessidade real nesta. Não há nenhuma afirmação de que temos aqui uma determinação do possível por si só, mas sim que estamos apenas na presença de uma propriedade contingente do nosso pensamento, a sua propensão para combinar aparições em objetos e contá-los como um só. A resolução literalmente utópica da contradição de ligação da unidade e multiplicidade em um reino nãofenomenal é um gesto para, como tão caracteristicamente é em todo o pós-kantianismo, mas não em favor de uma unidade schopenhaueriana sem multiplicidade. Em vez disso, no conhecimento de que tal unidade seria apenas um rastreamento feito em cima das ilusões “constitutivas da experiência” (o 'eu', o 'objeto'), Lange opta por um agnosticismo em relação a coisas em si mesmas que na posição afirma que, finalmente, pode não haver nada para resolver, a oposição de unidade e multiplicidade ser um efeito quimérico da "nossa organização".

O domínio de nossas representações extrapola a jurisdição do principium individuationis, portanto nem se limita e nem se submete a ele. Nossa experiência do mundo queda assim relativa e desancorada (unmoore) de uma unidade absoluta, cuja suposição é ilusória e até mesmo desnecessária, o que implica concluir, dentre outros, que a tão disputada oposição entre unidade e multiplicidade é tão somente uma 
ilusão criada por nossa própria sensação e percepção, isto é:

A oposição, metafisicamente estilizada por Schopenhauer, entre unidade e pluralidade poderia ser interpretada como um resultado de nossa organização psicofísica. Com isso está dado o passo que permite pensar o organismo como uma pluralidade de forças em conflito, e sua unidade como o efeito visível de uma acomodação provisória no interior desta pluralidade. (Lopes 2008, p. 45)

Lange dá com isso o "passo" decisivo para a noção pluralista de organismo, sustentáculo do pré-perspectivismo de Nietzsche em seus primeiros anos de produção. Embora de modo inconfesso, Nietzsche absorve boa parte do programa langeano e à luz dele formula os quatro argumentos centrais de ZT: "(1) a expulsão do teológico, (2) a negação da intencionalidade externa; (3) a relativização da individualidade, (4) a dissolução da antítese de mecanismo e teleologia” (Toscano, 2001, p. 52). Esses argumentos lançam as raízes que se farão sentir na formação madura do perspectivismo $^{16}$.

\section{CONCLUSÃO}

Apenas para fazer a mea culpa a favor de Nietzsche, a apropriação inconfessa de Lange, pelo menos em ZT, poderia ser justificada, em parte, por uma questão teórica. Ocorre que para Nietzsche o materialismo (e aqui Nietzsche talvez confunda o materialismo de Lange com o materialismo lato sensu ${ }^{17}$ ) estaria ancorado numa concepção atomista da rea-

\footnotetext{
${ }^{16}$ A rejeição da concepção teleológica e/ou da teoria organicista será assunto de vários textos posteriores como p. ex. FW/GC 109.

${ }^{17}$ Deve-se lembrar que Nietzsche conhecia bem o materialismo antigo, sobretudo Demócrito. Como comenta Toscano (2001, p. 48): "Suas objeções, nestas notas como em outras serão dirigiCont.
} 


\section{lidade, o que geraria igualmente problemas incontornáveis à compreensão de organismo. A despeito disso, a influência é incontestável e nos encaminha para uma conclusão simi- lar à de Toscano (2001, p. 60):}

O engajamento de Nietzsche com Lange, Schopenhauer e Kant sobre a questão da individuação finalmente leva-o para a questão do pré-individual, da vida como infinita multiplicidade produtiva. Para este problema ele aplica o que poderia ser chamado de um materialismo crítico ou transcendental, mantendo a demanda do materialismo para uma assimetria de produção - a individuação como representação deve ser contabilizada em termos nãorepresentacionais - e a vigilância da crítica contra as ilusões do antropomórfico - o pré-individual não pode simplesmente ser reduzido a matéria se o último for concebido de acordo com as ilusões objetivas que são constitutivas da própria representação (por exemplo, o átomo como principium individuationis). Assim, um materialismo transcendental para o qual a matéria não é transparente para o intelecto, um materialismo paradoxal sem matéria, deverá necessariamente se preocupar com o problema que Nietzsche via como o principal dos que ficaram sem solução pela redução da teleologia para a produção: a origem do intelecto. $\mathrm{O}$ problema da individuação como produção, assim, encontra-se atado a uma questão aparentemente circular: Como pode o intelecto ser o mecanismo que representa, logo o agente primário da individuação, e ele mesmo algo individualizado? No intervalo entre individuação pelo intelecto e individuação como produção, inicialmente inaugurado em Kant pelo organismo como a primeira crise da crítica, o esforço de Nietzsche, após o impasse da afirmação trágica da luta contra a "dor de individuação" será produzir uma ontologia experimental para resolver essa questão da origem do intelecto do ponto de vista da produção.

\section{Toscano (2001) considera que "materialismo crítico ou transcendental" seja uma boa nomenclatura para designar a}

das contra a crença acrítica na transparência da matéria, como evidenciada pela atomismo, "bem como contra o atendente conservadorismo ético produzido por tal crença". 
manobra teórica ensaiada por Nietzsche em ZT, numa dupla rejeição de materialismo e transcendentalismo. Essa manobra, porém, o colocará frente ao problema da origem do intelecto, que ainda segundo o comentador será por ele resolvido pelo ponto de vista da produção, com o desenvolvimento de uma "ontologia experimental".

Não encontro maiores objeções a tal conclusão, embora o adjetivo "crítico" me pareça preferível a "transcendental", por entender que toda a manobra operada por Nietzsche, recorrendo a Lange e a Goethe p. ex., é uma tentativa de dissociar-se do transcendentalismo, embora ainda se mantenha atado ao seu vocabulário. Aliás, esse comentário gera ainda a ocasião para uma última ressalva, concernente à interpretação de Marques (2003) que nos apoiou em boa parte de nosso percurso neste artigo.

Enquanto que para o comentador a "teoria do conhecimento" do perspectivismo de Nietzsche marca a radicalização do processo de autoafirmação do sujeito moderno, que dentre outros se constitui no limiar de antinomias como a dos fins da natureza, para nós o perspectivismo é justamente a insígnia da superação, do rompimento, da tresvaloração desse processo.

Marques (2003) equaciona ZT a alguns textos do período intermediário e maduro para vincular Nietzsche, ainda que numa postura de radicalização, à "teleologia fraca" de Kant, ancorada na ideia de conceito regulativo, com a diferença de que no perspectivismo de Nietzsche "cresce a componente de complexidade em detrimento dos elementos da unidade" (Marques, 2003, p. 56).

Neste ponto parece-me especialmente onerosa a ausência de uma interlocução de Marques (2003) com Lange, 
como também a indistinção entre os textos jovens e maduros, pois segundo pensamos não há apenas uma relação de "proporcionalidade", uma "crescente de complexidade" a separar, mas também a unir Kant e Nietzsche. Com o perspectivismo, e isso se faz perceber quando contrastamos $\mathrm{Ni}$ etzsche por exemplo a Teichmüller, a própria noção de regulativo que sustenta a teleologia kantiana se torna "fraca”, por falta de um termo melhor, na medida em que seu sustentáculo, a estrutura transcendental do sujeito e seus apriori é posto em xeque como elemento ficcional ${ }^{18}$.

Embora questionável em alguns sentidos, como pela leitura enviesada e de segunda mão da obra de Kant (através de K. Fischer e Schopenhauer, por exemplo), Zur Teleologie apresenta alguns "insights" de notável relevância, na medida em que ensaia uma das primeiras versões da noção de organismo que também no período maduro balizará o perspectivismo. Além disso, a coletânea já chama a atenção para a natureza ficcional e utilitária dos empreendimentos metafísicos, elemento presente em toda a filosofia de Nietzsche.

Pensando por este prisma, a teleologia em ZT é para Nietzsche um exemplo emblemático de como uma noção metafísica, um conceito de caráter universal que acredita se circunscrever no âmbito puramente cognitivo, na verdade é

\footnotetext{
${ }^{18}$ Este é um dos principais pontos em que nossa interpretação difere da de Marques (2003). Em virtude de seu tratamento "indistinto" dos textos nos diferentes períodos, que em parte se justifica pela sua ênfase no período jovem, o comentador português acaba por estender uma interpretação que seria mais compatível com o período jovem para o período maduro. Para evitar esta equivalência diferencio em minha tese de doutorado o pré-perspectivismo e o per-spectivismo dos dois primeiros períodos do perspectivismo do período maduro. Em virtude disso, caso a ideia de uma teleologia fraca se aplicasse somente ao pré-perspectivismo, nos termos de nossa diferenciação, sua afirmação nos pareceria menos problemática. Cf.: DALLA VECCHIA, Ricardo B. O(s) perspectivismo(s) de Nietzsche. Tese de Doutorado. Campinas-SP: 2014.
} 
apenas uma perspectiva particular e que possui um interesse de ordem diversa a da cognição. Nestes apontamentos de 1868 tal interesse é identificado e denominado apenas como "estético", porém, futuramente, Nietzsche irá reconhecer a sua motivação essencialmente moral ${ }^{19}$.

$\mathrm{O}$ que faz de ZT um texto de importância estratégica não é só a pergunta pela possibilidade de rejeitar o (ou a metafísica do) juízo teleológico sem recorrer a um domínio igualmente metafísico, mas o problema que dela decorre. Seja apoiado em Goethe e Lange ou mesmo em uma noção própria da vontade de poder, a discussão sobre a finalidade da natureza colocará Nietzsche diante de um dos principais problemas que sua filosofia precisará enfrentar, a saber, do estatuto/valor dos produtos subjetivos da razão. Toda a investigação que empreendemos sobre a tensão entre teleologia e mecanicismo se justifica quase que exclusivamente por apontar para esse problema.

$\mathrm{O}$ itinerário pessoal, intelectual e neste momento também profissional de Nietzsche no final da década de 1860, embora o permitam vislumbrar o problema, não favorecem uma resposta a ele nos moldes "halb philosophisch, halb naturwissenschaftlich" característicos de ZT. Como o projeto de ZT foi abandonado com a mesma intensidade com que fora elaborado, seus apontamentos nos fornecem apenas um indicativo de como, em 1868, Nietzsche compreendia o problema dos limites do conhecimento e apontar para uma espécie de protótipo do perspectivismo, na medida em que estabelece que o orgânico é apenas uma noção ficcional for-

${ }^{19}$ Por exemplo em JGB/BM, 6. 
jada pelo intelecto, e que os produtos subjetivos da razão não passam de ficções "estéticas".

Abstract: By analyzing the collection of notes "Zur Teleologie" this article suggests the existence of a "proto-perspectivism" in the fictionalist conception of organism formulated by Nietzsche in the late 1860s. Our investigation begins with an exposition of the opposition between Mecanicism and Teleology in modernity, briefly analyzes Kant and Schopenhauer's positions on it and then contrasts them with Nietzsche's position.

Keywords: Nietzsche; Kant; teleology; perspectivism.

\section{REFERÊNCIAS}

ARALDI, C. Organismo e arte na filosofia de Nietzsche. In: Philosophica. Num. 29. Lisboa: 2007, pp. 35-47.

BROBJER, Thomas. Nietzsche's philosophical context: an intellectual biography. Chicago: University of Illinois Press, 2008.

DALLA VECCHIA, Ricardo B. $O(s)$ perspectivismo(s) de Nietzsche. Tese de Doutorado. Campinas-SP: 2014.

GERHARDT, Volker; HEROLD, Norbert. Perspektiven des Perspektivismus. Würzburg: Königshausen und Neumann, 1992.

GREEN, Michael Steven. Nietzsche and the Transcendental Tradition. Urbana \& Chicago: University of Illinois Press, 2002. (International Nietzsche Studies Series).

HARTMANN, Nicolai. Teleologischen Denken. Berlin: De Gruyter, 1966.

HILL, R. Kevin. Nietzsche's Critiques: The Kantian Foundations of his Thought, Oxford University Press, 2003. 
JANZ, C. P. Nietzsche biographie Enfance, Jeunesse, Les Annees Baloises. Trad. Marc B. de Launay. Paris: Gallimard, 1984.

KANT, Immanuel. Crítica da faculdade do juízo. 3 ed. Trad. Valério Rohden e Antonio Marques. Rio de Janeiro: Forense Universitária, 2012.

. Crítica da razão pura. 6 ed. Trad. Manuela Pinto dos Santos e Alexandre F. Morujão. Lisboa: Fundação Calouste Gulbenkian, 2008.

. Werke in Zwölf Bande. Ed. W. Weischedel. Frankfurt: Surkamp, 1991.

KAULBACH, F. Philosophie des Perspektivismus: 1. Teil: Wahrheit und Perspektive bei Kant, Hegel und Nietzsche. Tübingen: Mohr, 1990.

LOPES, Rogério Antônio. Ceticismo e vida contemplativa em Nietzsche. Tese de Doutorado. Belo Horizonte: 2008.

MARQUES, Antônio. A filosofia perspectivista de Nietzsche. São Paulo: Discurso Editorial; Ijui: Ed. Unijui, 2003.

NIETZSCHE. F. Sämtliche Werke: Kritische Studienausgabe in 15 Bänden (KSA). Hrsg. G. Colli und M. Montinari. Berlin/New York: DTV \& Walter de Gruyter, 1999.

. Werke: Kritische Gesamtausgabe (KGW). 36 Bände. Herausgeben Giorgio Colli e Mazzino Montinari. Berlim: De Gruyter, 1967-2001, Bd. I.

. Sämtliche Briefe. Kritische Studienausgabe (KSB). Hrsg. G. Colli u. M. Montinari. Berlin/New York: DTV \& Walter de Gruyter, 1986. 
SMALL, R. Nietzsche in Context. Aldershot: Ashgate, 2001.

SCHOPENHAUER, A. O mundo como vontade e como representação. Trad. Jair Barboza. São Paulo: Unesp, 2005.

TOSCANO, A. The Method of Nature, the Crisis of Critique. The Problem of Individuation in Nietzsche.s 1867/1868 Notebooks. In: Pli: The Warwick Journal of Philosophy. Vol. 11 (2001): pp. 36-61. 